\title{
HISTORICAL SURGICAL INSTRUMENTS IN THE MUSEUM OF THE ROYAL COLLEGE OF SURGEONS OF ENGLAND (2)
}

\author{
W. E. Thompson, London, ENGLAND
}

The collection of surgical instruments and apparatus in the museum of the Royal College of Surgeons of England has gradually been built up, by gifts and bequests, over the past 1.50 years. It seems that no attempt was made to classify the instruments until 1871, when a separate room was provided and Mr R. Williams, of Messrs Weiss and Son, undertook the work. In $1878 \mathrm{Mr}$ Walter Pye, F.R.C.S., compiled a manuscript list giving names and numbers, and, in some cases, short details but no descriptions. Then, in 1912, Mr Alban H. (i. Doran, F.R.C.S., was asked to prepare a descriptive catalogue. Into this task Mr Doran put the whole of his energy and profound scholarship, completing the work shortly before his death in 1927. A glance through the several volumes, in print or typescript, will enable one to see the enormous amount of research into medical literature and College records that has gone into its compilation. It is from this catalogue that the greater part of the information in these articles was obtained.

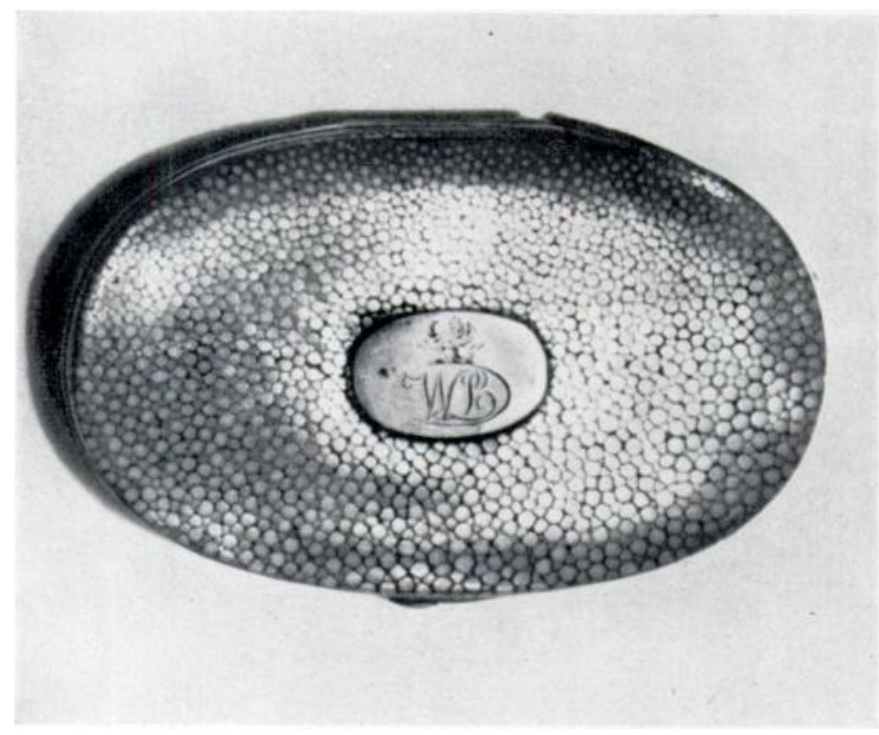

Fig. 13

Cerate case formerly belonging to William Long, F.R.S., Master of the College in 1800 .

A cerate case (Fig. 13) of white metal covered in polished green shagreen was formerly the property of William Long, F.R.S., Master of the College in 1800. On the upper surface of the lid is a silver plate engraved with the initials "W. L." and crest, and the words "Mr Long. July 7th, 1818" in the handwriting of William Clift (first Conservater of the Museum, 18(0-184:) are scratched on the under surface. The interior of the case is divided into four ccmpartments, one of which is subdivided into three smaller cells. It was presented by Mrs I.ong in 1818 .

A surgeon's pocket instrument case (Fig. 14), dating from about the middle of the eighteenth century, is made of white metal and polished green shagreen, the exposed metal 


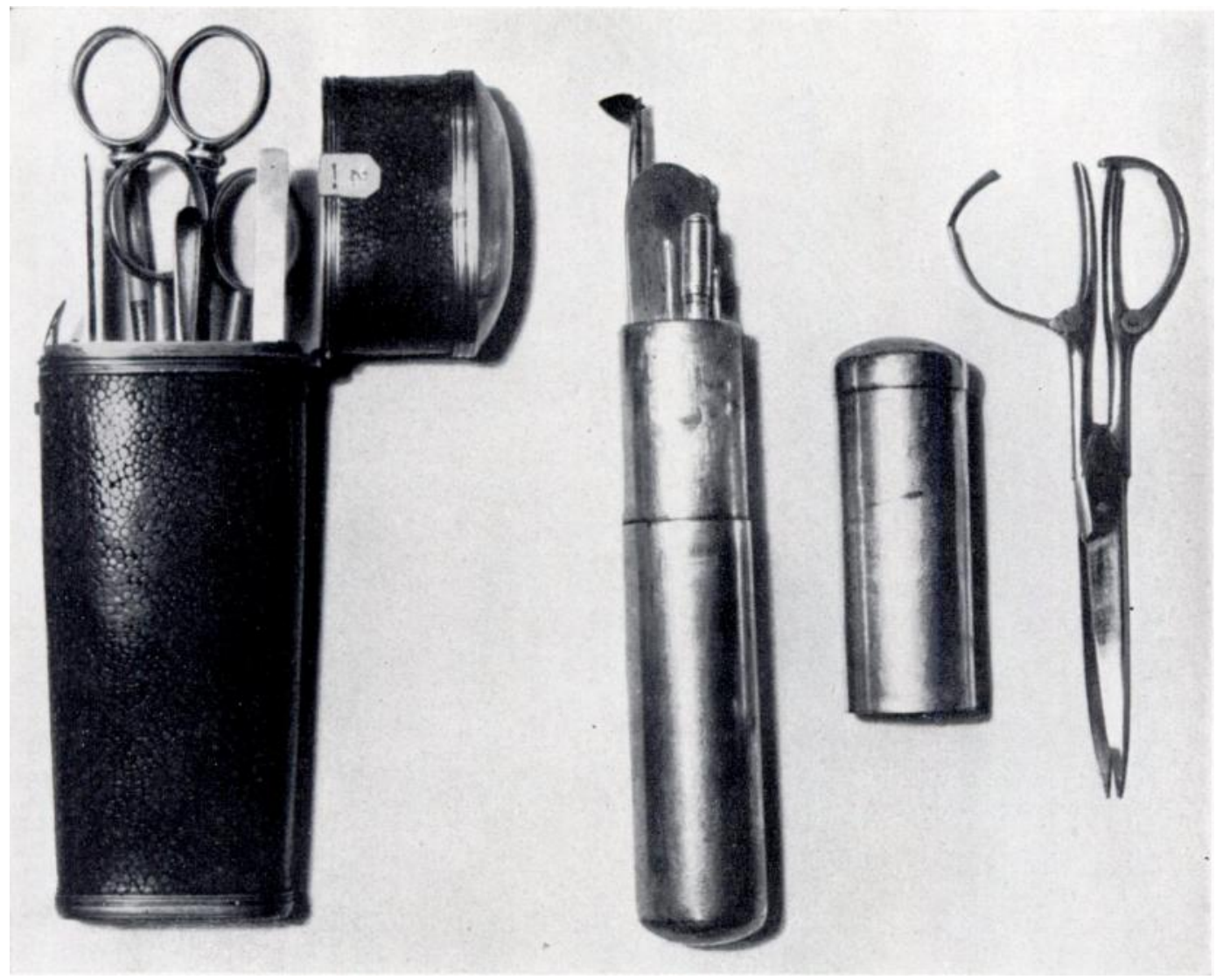

Fig. 14

Leff-A surgeon's pocket instrument case (mid eighteenth century. Right-A cylindrical silver pocket case of surgical instruments (late eighteenth century).

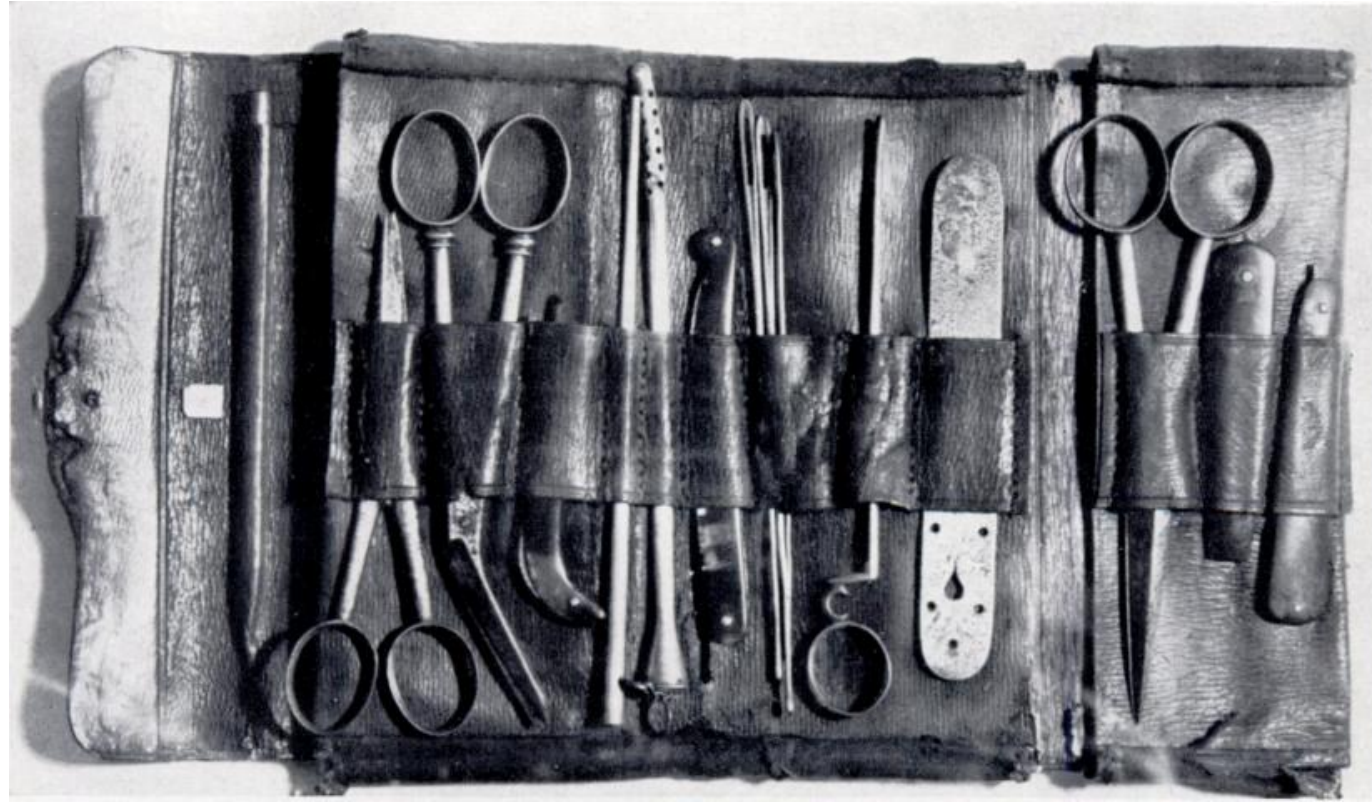

Fig. 15

IIungo Park's surgical pocket case.

vol. $35 \mathrm{~B}$, No. 3, Augest 1953 
parts being silver plated. It contains two pairs of scissors (one having curved blades), dressing forceps, ear scoop and director, and a spatula for spreading ointments; three empty spaces held instruments that are now missing. This case formerly belonged to $\mathrm{Mr}$ Hector, of Birmingham, a schoolfellow and friend of Dr Samuel Johnson.

Another interesting case, of the late eighteenth century, is made of silver and completely cylindrical (Fig. 14). It contains a pair of scissors (each ring handle of which is jointed to facilitate packing), dressing forceps, spatula, two flexible probes, female catheter, fleam or gum lancet, and a hollow white metal rod with a ring at one end to hold a quill containing caustic; the opposite end of the rod bears a screw cap covering a receptacle for red oxide of mercury. The case was presented by G. L. Wood, who qualified M.R.C.S. in 1819, and was used by the father or grandfather of the surgeon to whom the donor was apprenticed early in the nineteenth century.

An historical surgical pocket case is the one which belonged to Mungo Park (1771-1806), the famous African explorer (Fig. 15). Mungo Park received his medical training first as an

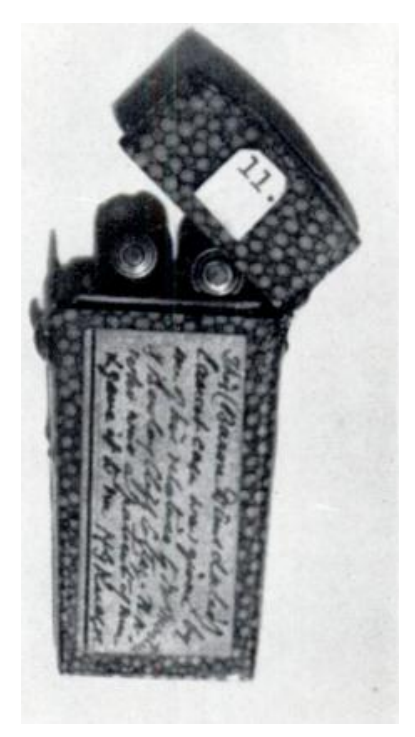

FIG. 16

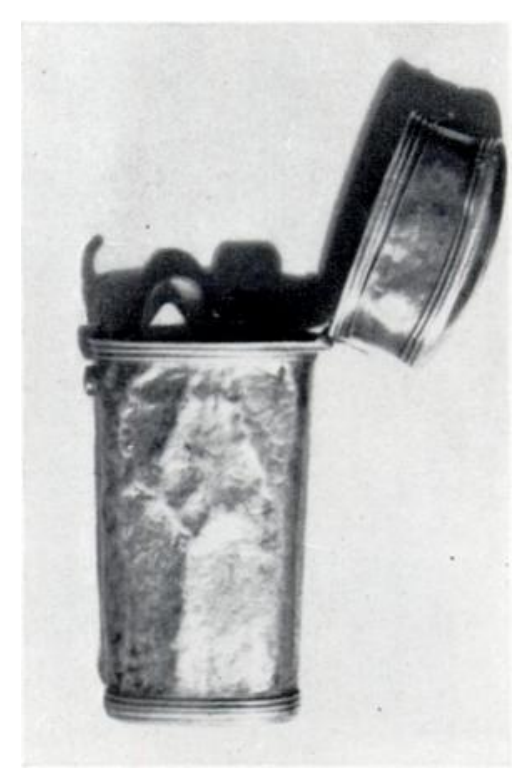

FIG. 17

Figure 16-Baron Dimsdale's lancet case of wood covered with shagreen. Figure 17-Silver lancet case carried by a surgeon when imprisoned in the Black Hole of Calcutta.

apprentice to Mr Thomas Anderson, a surgeon of Selkirk, and then at Edinburgh Lniversity where he served three sessions. He presented the case to Sir Anthony Carlisle in 180:). Sir Anthony Carlisle gave it to Mr Bartley, surgeon of Mitcham, Surrey. His accompanying letter, now preserved in the Library of the College, reads: " I beg to thank you for your great kindness, skill and attention to Mrs Carlisle's unfortunate health. Allow me to offer you a small remembrance of me. It is the pocket case of instruments which belonged to Mungo Park and which he gave me for a professional memento. In using this case, think of both of us." It is signed "A. Carlisle" and dated April 6, 1816. Mr Bartley's daughter presented the case to the College in 1902. The case is of red leather and contains the following instruments: two pairs of steel scissors and a third angled pair with steel blades and handles of white metal, director with ring handle, steel spatula, abscess lancet, tenaculum, gum lancet, blunt-pointed curved bistoury, three-eyed probes, dressing forceps (now missing), blow-pipe and lead pencil. A first edition of Mungo Park's Travels in the Interior Districts of Africa, published in 1799, is in the College Library. 
Other pocket cases preserved in the Collection include that formerly belonging to Sir David Dundas (1749-18:6), Master of the College in 1804, 1811,1819 , and others that belonged to Robert Liston (1794-1847), Sir William Fergusson (1808-1877), Sir William Flower (18:31-1899) (Conservator of the Museum, 1861-1884), purchased before he proceeded to the Crimea where he served as a surgeon during the war, and Thomas R. College (1796-1879), one of the founders of Medical Missions in the East, all the instruments having engraved silver

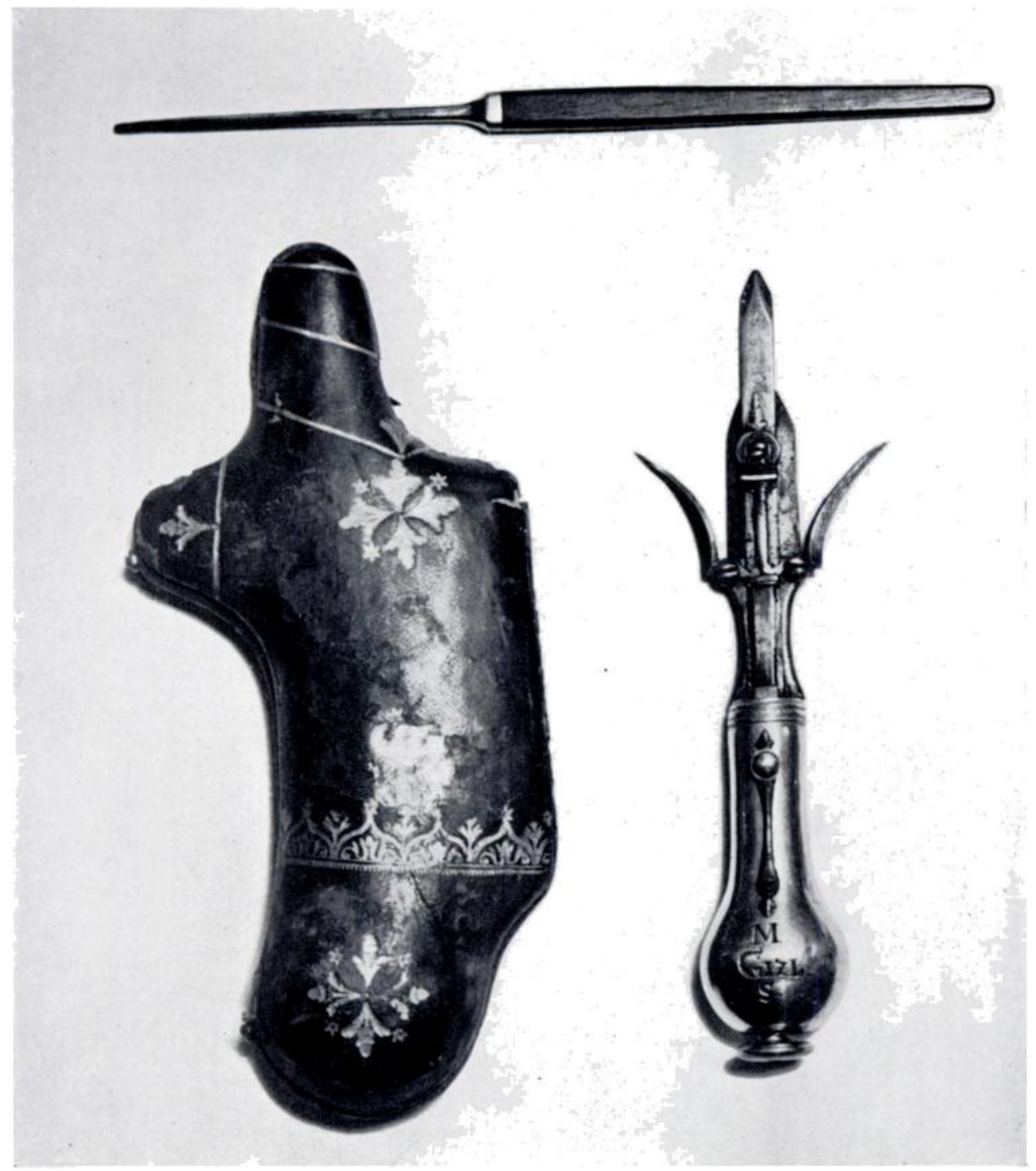

FIG. 18

Top-Cerebral knife used by Sir Rickman J. Godlee in the first operation for tumour of the brain. Below-Abscess opener probably dating from the seventeenth century.

gilt mounts. In addition there are a case presented to Dr Metcalfe when he took his degree in medicine at Cambridge in $\mathbf{1 7 6 0}$ and given to the Museum by his great-granddaughter in 1936; and part of the contents of a case belonging to Sir John Erichsen (1818-1896), President 1880 , the leather case and some of the instruments having been destroyed by enemy action in 1941 .

The Collection includes some interesting lancet cases. One belonged to Baron Dimsdale vol. 35 B, No. ?, AUGUSt 1953 
(Thomas Dimsdale, M.D., 1712-1800). His lancet case, made of wood covered with polished green shagreen, contained two lancets (Fig. 16). On the case was originally pasted a printed note: "The fee of fees, however, was that received by Dr Dimsdale in 1768 for inoculating the Empress Catherine and her son at Petersburg. It consisted of $\mathfrak{1 2 , 0 0 0}$ paid down, a pension of $\mathfrak{f 5 0 0}$ a year for life, and a dignity of a Baron of the Empire." A manuscript note pasted on the case reads: "This [Baron Dimsdale's lancet case was given by one of his

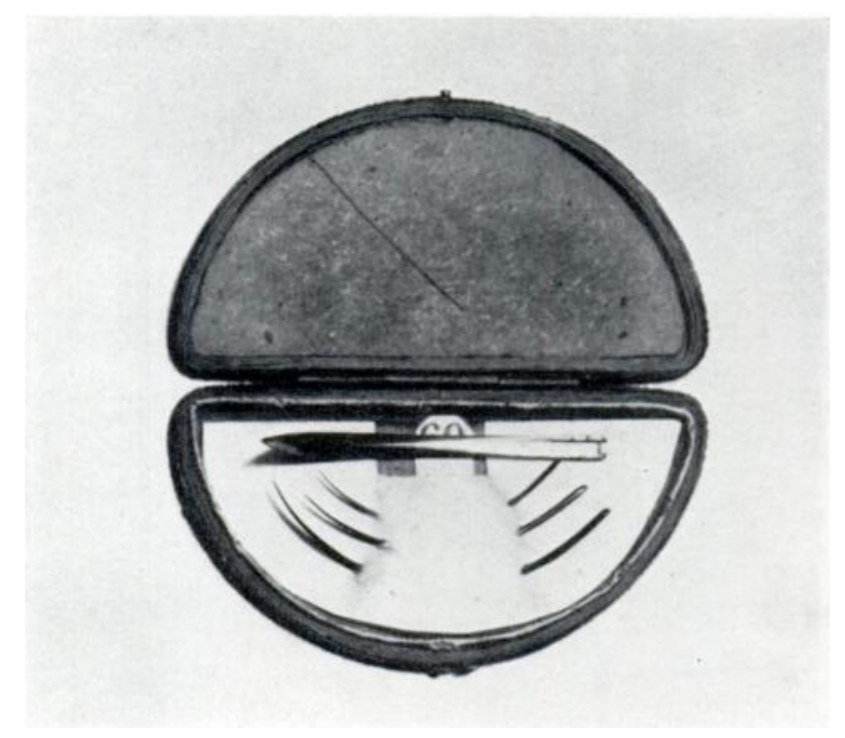

FIG. 19

John Ai rencthy's needles.

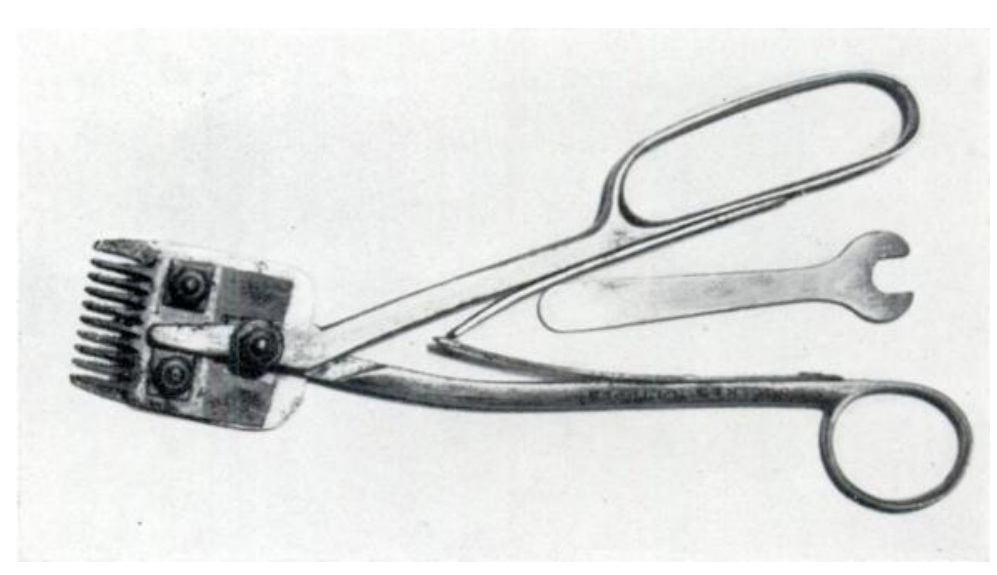

FIG. $2 i r$

Dr A. J. Balmanno Squire's hair clipper.

relatives to Mr Martin of Bewlay (liff Cottage, N.W., who was a patient of mine and gave it to me. H. G. Knaggs." Dr Knaggs presented it to the Museum in $\mathbf{1 8 9 4 .}$

Another lancet case, in silver, contained four lancets, three of which are mounted in mother-of-pearl and the fourth in tortoise-shell. It belonged to John Rose, a surgeon of Eye, Suffolk, and was given to the Museum by Sir James Sherrington, O.M., in 1929 (Fig. 17). It originally belonged to a surgeon in India who was imprisoned in the Black Hole of Calcutta and had the case in his pocket at the time. His initials "T. J." are engraved on the lid. 
An instrument of great historical interest is the cerebral knife used by Sir Rickman Godlee in the first operation for tumour of the brain, which was carried out at the Hospital for Epilepsy and Paralysis, Regent's Park, London, on November 25, 1884 (Fig. 18). The tumour was located as a result of the experimental work of Sir David Ferrier. Details of the case were published in the Lancet (1884). A dinner held to commemorate the jubilee of the operation was also reported in the Lancet (1934). The knife was presented by Sir Rickman J. Godlee, Bt., to the Museum in 1921.

An abscess opener probably dating from the seventeenth century is of particular interest (Fig. 18). It is preserved in a wooden case made to correspond to its shape with the spurs extended. The case is covered with leather with gilt marking and a falcon with head turned back. The letters "Gizl" with an " M" above and an "S" below are cut on the brass handle of the instrument. When the piston at the base of the handle is withdrawn the central pointed steel bar travels backwards along a groove in the steel guard plate and the spurs, one on each side, are drawn inwards to lie against it. The spring mechanism in the handle is held in check by pressure on a thumb-stud on the handle, and on release the steel bar flies forwards and the spurs outwards. This instrument was presented to the Museum in 192.2 as a rare and ancient form of abscess opener. No history of its inventor or use had been obtained.

Packed in a sharkskin case, semicircular in shape, are three curved needles of a pattern seen in Savigny's Instruments used in the Practice of Surgery (1798) and a seton needle also illustrated in the same work (Fig. 19). These needles were given by John Abernethy to Mr Thomas Wormald (1802-1873), surgeon to St Bartholomew's Hospital.

The last instrument to be mentioned in this contribution is the hair clipper of Dr A. J. Balmanno Squire (M.R.C.S. 1858), presented by the makers, Messrs Weiss and Son, in 1881 (Fig. 20). It was devised for cutting off the hair of the scalp in skin diseases, and is said to be the first instrument of the kind invented.

\section{REFERENCES}

CALENdar of the Royal College of Surgeons of Englard (1951): London: Taylor \& Francis Ltd.

Dorax, A. G. H.: Descriptive Catalogue of the Surgical Instruments in the Museum of the Royal College of Surgeons of England. (Typescript, Library, Royal College of Surgeons of England.)

LANCET (1884): Excision of a Tumour from the Brain, ii, 1091).

LANCET (1934): The Rickman Godlee Dinner, ii, 1,255.

PlarR's Lives of the Fellows of the Royal Col!ege of Surgeons of England (1930): Bristol: Printed and Published for the Royal College of Surgeons by John Wright \& Sons L.td.

Savigny, J. H. (1798): A Collection of Engravings Representing the Most Modern and Approved Instruments Used in the Practice of Surgery. I.ondon. 